say that it is easy for me to wear shorts both because I live and work in the Provinces and, as a community physician, I am not a "real doctor." Well, we do have sartorial standards in the Provinces-indeed, they are often higher than in London-and we community physicians have our standards also. I am of ten called on to pronounce on some policy in housing or social service debates in which my status as doctor is all-important. Will the sight of my knees reduce my credibility?

Society changes and we must change with it. It is not so much decaying as melting under our climatic change. I was in Covent Garden Opera House last week and by the end of "Don Giovanni" every man was without jacket and tie (except, interestingly enough, $\mathrm{Mr}$ B Levin). Even MCC members are now allowed to shed their jackets.

If doctors do adopt short trousers it is wise to let every registered practitioner wear them without considering the effect that the sight might have on some patients. Should the General Medical Council develop a supplementary register of approved short-wearers or would this infringe medical freedom? Should community medicine study the effects of short-wearing before any action is taken or is this the thin end of the wedge of medical audit by the administration?

Now is the time to debate such issues. We have nothing to lose but our trousers.

Oxford

J A M Gray

\section{T Lymphocytes in kidney allograft recipients}

SIR,-Dr T Tursz and others (3 April, p 799) report the results obtained with spontaneous sheep erythrocyte (E) rosette test carried out on lymphocytes from 14 renal allograft recipients on the occasion of 17 rejection episodes. They observe that most $(12 / 17)$ rejection crises were associated with a rapid decrease in $\mathbf{E}$ rosettes before steroid treatment and that clinically successful steroid pulses induced an increase in $\mathrm{E}$ rosettes.

We have determined the absolute number and the percentage of $T$ and $B$ peripheral blood lymphocytes 1-3 times a week for 2-5 months in 30 patients with renal transplant (480 observations). $T$ cells were identified by E-rosette formation ${ }^{1}$ and $B$ cells by EACrosette formation" and by immunofluorescent staining of surface immunoglobulins (Ig). ${ }^{3}$ Twenty-five rejection episodes occurred in 21 patients. Contrary to the findings of $\mathrm{Dr}$ Tursz and his colleagues no significant change was found in the relative and absolute numbers of $T$ cells during rejection before steroid-pulse therapy.

Intravenous pulses of methylprednisolone, $1 \mathrm{~g}$ every $48 \mathrm{~h}$, used in the management of acute rejection, induced profound effects on the circulating lymphocytes. There was a steep though transient fall in the total lymphocyte count, maximal at $12 \mathrm{~h}$ after steroid administration, when, on average, only $49 \pm$ $17^{\circ}$ of the cells initially present remained in circulation (P.001). This lymphocytopenia was, however, selective in that, despite a fall in the absolute numbers of both $T$ and B lymphocytes, there was a proportionately greater depletion of circulating $T$ lymphocytes, $40 \pm 16^{\circ}$ of the initial number of $\mathrm{E}$ rosettes remaining at $12 \mathrm{~h}$, whereas $72 \pm 30 \%$ of $\mathrm{Ig}+$ lymphocytes were still present at that time $(P-0.01)$. Thus the proportion of $\mathrm{T}$ cells declined after methylprednisolone (from $62 \cdot 1 \pm 10 \cdot 7^{\circ}$, to $48 \cdot 6 \pm 8 \cdot 7^{\circ}$, (P. 0.01 ) whereas the proportion of $\mathrm{B}$ cells actually rose (from $24 \cdot 1 \pm 7 \cdot 7^{\circ}$ o to $36 \cdot 7 \pm 6 \cdot 8^{\circ}$ o (p $0.005))$. The lymphocytopenia and $T$-cell depression were still present, though less marked, at $24 \mathrm{~h}$, but the counts had returned to the original levels $48 \mathrm{~h}$ after methylprednisolone administration. The most likely explanation of this steroid-induced lymphocytopenia could be a redistribution of cells from the circulation to other body compartments (bone marrow ?), as suggested by experimental models ${ }^{45}$ and studies in human beings."

Our results confirm the "need for caution" suggested by Dr Tursz and his colleagues in using the $\mathrm{E}$ rosette test and, more generally, $B$ and $T$ cell markers for monitoring antigraft immunity in renal allograft recipients. However, our findings are different in that in most rejection episodes the number of $\mathrm{E}$ rosettes remained stable and steroid pulses induced a profound though transient lymphocytopenia. This latter finding may be explained by the fact that in our patients the determinations were performed every $12-24 \mathrm{~h}$ after steroid pulses.

\section{A Cantaluppi}

Sezione di Nefrologia e Dialisi Ospedale Policlinico Milan, Italy ${ }^{1}$ Jondal, M, Holm, G, and Wigzell, H, fournal of

- Stjernswärd, J, et al, Lancet, 1972,

${ }^{3}$ Pernis, B, Forni, L, and Amante, L, fournal of Experimental Medicine, 1970, 132, 1001

${ }^{4}$ Cohen, J J, fournal of Immunology, 1972, 108, 841

5 Fauci, A S, Transplanation Proceedings, 1975, 7, 37. estipation, 1975, 55, 22.

\section{Further thoughts on hypnotics}

SIR,-Dr John R Bennett's "Personal View" (May 29, p 1338) was most illuminating, especially his comments in the first and last paragraph-for example, "all hypnotics have been forbidden on my wards, except on my personal direction." It would be enlightening to know if other consultants engender similar attitudes or whether they turn a blind eye while innumerable housemen, either on their own initiative or egged on by nursing staff adept in the art of "pharmacological overkill," hand out Welldorm (dichloralphenazone), "Moggies" (nitrazepam), or the inordinately expensive Heminevrin (chlormethiazole) with thoughtless abandon.

Taking Dr Bennett's initial comments a step further I would suggest that hypnotics are being prescribed quite uncritically in the institutions which ought to know better, with little thought given to specific indications or long-term effects. The great majority of prescriptions for hypnotics are based on invalid indications, the main one being noise, the most inexcusable reason of all. The noise is created by the chattering of animated, thoughtless night staff together with the flinging of metal bed pans around a sluice room accompanied by a symphony of plumbing; jack-booted night ward rounds by doctors conversing in anything but discreet tones; and the use of ward lighting after hours in a way which would put Piccadilly Circus to shame. The remedy is self-evident, but woefully the alternative, damping the patients' responses, is seen as a convenient, natural method.

Solicitous insistence on eight hours plus of slumber for hospital inpatients with their mundane daily timetable is evidently pointless, as their nocturnal spells are bound to be shortened at times. Old age precludes the hours of sleep we take as normal and it is consequently ludicrous to compel prolonged nights on such patients artificially by means of drugs. The occasional irregular night is insignificant, except to those individuals who regard sleep in the same light as the desirability of opening their bowels by the clock. And, finally, the practice of issuing hypnotics on request I find reprehensible.

Hospitals are moving, and being moved, steadily to a situation where every aspect of mental and physical performance in hospital is catered for pharmacologically. Where we should be making efforts to reduce polypharmacy and the size of the patient's drug chart, with its inherent problems of side effects and drug interactions, we are needlessly adding to it.

Ham Green Hospital,

G BENFIELD Bristol

\section{What do community physicians do?}

SIR,-Dr W S Parker (26 June, p 1588) has told us what the medical officer of health used to do. Dr P H M Carson (12 June, p 1469) and many other members of the profession are anxious to know what community physicians do now, especially as Dr Parker informs us that Whitehall has tied their hands behind their backs.

Holywe!l, Clwyd

A RoBerts

\section{Compulsory seat belts}

SIR,-I read with interest Dr John Knight's letter from Victoria (5 June, p 1391). Their improved road accident statistics following the compulsory wearing of seat belts is encouraging in view of our Government's pending legislation. Here too there is a strong lobby against the Bill on several grounds, including the infringement of liberties. The views of statisticians and politicians are being voiced but not those of road accident victims, particularly those who have been cut by windscreen glass. I have found it rewarding to study 20 such patients. None of them had been wearing a seat belt at the time of the accident. They are 12 men and 8 women of average age 22 years. Eighteen of them had been on short journeys-within 20 minutes of home-and only two were on longer journeys. Twelve were drivers and eight front-seat passengers.

Eighteen of the 20 volunteered the information that the wearing of seat belts would probably have prevented the injury caused by their contact with the windscreen and fascia-only two patients disagreed. Sixteen of these 18 patients attributed their non-wearing of seat belts to laziness, their hurry to get somewhere, or the late hour. None found seat belts uncomfortable. The remaining two of these 18 patients did not have seat belts fitted in their cars.

Now, many months and years later, only 10 of these patients regularly wear seat belts. Thus many of this select group of road 